\title{
Comparison of candidate architectures for future distributed propulsion aircraft
}

\author{
Catherine E. Jones, Patrick J. Norman, Stuart J. Galloway, Michael J. Armstrong and Andrew M. \\ Bollman.
}

\begin{abstract}
Turbine engine driven distributed electrical aircraft power systems (also referred to as Turboelectric Distributed Propulsion (TeDP)) are proposed for providing thrust for future aircraft with superconducting components operating at $77 \mathrm{~K}$ in order for performance and emissions targets to be met. The proposal of such systems presents a radical change from current state-of-the-art aero-electrical power systems. Central to the development of such power systems are architecture design trades which must consider system functionality and performance, system robustness and fault ride-through capability, in addition to the balance between mass and efficiency. This paper presents a quantitative comparison of the three potential candidate architectures for TeDP electrical networks. This analysis provides the foundations for establishing the feasibility of these different architectures subject to design and operational constraints. The findings of this paper conclude that a purely AC synchronous network performs best in terms of mass and efficiency, but similar levels of functionality and controllability to an architecture with electrical decoupling via DC cannot readily be achieved. If power electronic converters with cryocoolers are found to be necessary for functionality and controllability purposes, then studies show that a significant increase in the efficiency of solid state switching components is necessary to achieve specified aircraft performance targets.
\end{abstract}

Index Terms-Distributed electrical aircraft propulsion, superconducting power systems, turbo-electric distributed propulsion

\section{INTRODUCTION}

A IR travel is predicted to continue to rise steadily, with air passenger numbers expected to continue to rise by more than $5 \%$ per year [1]. This predicted growth has provided motivation to develop future aircraft which have a lower environmental impact and better performance, with lower emissions, lower fuel-burn and lower noise [2]. Additionally if future aircraft are able to take off from shorter runways, then a higher number of airports would be available to facilitate this flight traffic. This would lead to the availability of more direct flights and reduce environmental impact by significantly reducing fuel burn [5]. However, it

Paper submitted for review on $27^{\text {th }}$ of August 2015. This work has been undertaken within the Rolls-Royce University Technology Centre for Electrical Power Systems, and as part of NASA RTAPS NNC13TA77T.

C.E. Jones, P.J. Norman, and S.J. Galloway are with the Institute for Energy and Environment, University of Strathclyde, 204 George Street, Glasgow, UK G1 1XW. (e-mail: catherine.e.jones@ strath.ac.uk)

M. J. Armstrong and A. M. Bollman, are with Electrical Power and Control Systems, Rolls-Royce North America, Indianapolis, IN, USA. would also require a more co-ordinated approach to minimise fuel burn with a limited infrastructure [3].

To accommodate future air traffic demands, ambitious performance and fuel emissions targets for future aircraft have been set by both the European Union [3] and the US (NASA) [5] (outlined in Table 1). The NASA targets form an intermediary point between the two sets of criteria set out by the EU. It has been proposed in the literature that it may be possible to meet the ambitious targets shown in Table 1 , if distributed electrical propulsion systems for aircraft can be developed [2],[6].

Power system architecture, protection, redundancy are highly interdependent, and will ultimately impact on the performance of the aircraft. A holistic approach is required to optimise system performance. Hence there is a timely requirement to evaluate the performance of the TeDP power system as a whole, and in doing so provide valuable systemslevel insight at the pre-design stage.

The remainder of this paper is structured as follows: Sections II and III will provide appropriate background to aero-electrical and TeDP and introduce three candidate architectures which have been presented to date in the literature. Section IV will describe the pre-design analysis methodology adopted to carry out the mass and efficiency analysis. Section $\mathrm{V}$ provides a comparison of the three candidate architectures, taking account of the key trade-offs between performance controllability and design. The impact of electrical protection systems in this whole systems methodology are identified and discussed. A discussion on the work and result is given in Section VI and conclusions drawn in Section VII.

\section{TEDP OVERVIEW}

It is proposed that the electrical power system for a distributed electrical propulsion system is provided by generators driven by the gas turbines, with two generators driven by each engine [10]. The engines are positioned on the wingtips to optimise the reduction of lift induced drag, reduced wake vortices and wing structure mass [6],[10]. Multiple propulsor motors are positioned on the rear of the aircraft to take advantage of boundary layer ingestion and wake-fill in [11]. These combined effects significantly reduce fuel burn. 
This document is a pre-print which was accepted for publication in IEEE transactions on Applied Superconductivity on the $1^{\text {st }}$ of February 2016, and as such is subject to IEEE copyright.

TABLE I

NASA AND EUROPEAN UNION COMMISSION PERFORMANCE GOALS

\begin{tabular}{|l|c|c|c|c|c|}
\hline Source & $\begin{array}{l}\text { Target } \\
\text { date }\end{array}$ & Noise & $\begin{array}{l}\text { LTO } \\
\text { NO }_{\mathbf{x}}\end{array}$ & $\begin{array}{l}\mathbf{C 0}_{2} \text { per } \\
\text { pax }\end{array}$ & $\begin{array}{l}\text { Fuel } \\
\text { burn }\end{array}$ \\
\hline $\begin{array}{l}\text { EU } \\
\text { Advisory } \\
\begin{array}{l}\text { Council for } \\
\text { Aeronautics } \\
\text { research }\end{array}\end{array}$ & 2020 & $-50 \%$ & $-80 \%$ & $-50 \%$ & - \\
\hline $\begin{array}{l}\text { NASA N+3 } \\
\text { Advanced } \\
\text { Aircraft } \\
\text { Concepts }\end{array}$ & 2025 & $-71 \mathrm{~dB}$ & $-75 \%$ & - & $-70 \%$ \\
\hline $\begin{array}{l}\text { EU } \\
\text { Commission } \\
\text { "Flightplan } \\
\text { 2050" }\end{array}$ & 2050 & $-65 \%$ & $-90 \%$ & $-75 \%$ & - \\
\hline
\end{tabular}

TeDP presents as a radical departure from the state-of-theart aero-electrical power systems. Firstly, it requires a significant increase in the generating capacity for normal operation on-board an aircraft from 1.5MW for a state-of-theart more-electric aircraft [12] to up to 50MW for a distributed propulsion aircraft [9]. Secondly, it is well documented in the literature that such electrical power systems are expected to be superconducting in order to meet the high power density requirements necessitated by the aerospace application [2],[7],[9]. Both of these proposed radical changes to aeroelectrical power systems present a number of technical challenges. Central to overcoming both of these challenges, is the requirement to develop a reliable superconducting aeroelectrical power network which be sufficiently light and efficient such that the lower fuel burn benefits of a distributed electric aircraft (compared to a conventional MEA) are maintained [7],[11].

Superconducting electrical machines have been proposed for distributed electrical power systems as it is predicted that they will enable high enough power densities and efficiency levels to be reached [14]. Interfacing the electrical machines to the power system via power electronic converters enables the power system to function as a continuously variable transmission system. The shaft speeds of the generators and propulsor motors are decoupled and run at their respective optimised speeds [11].

It is proposed that the full electrical system is a high temperature superconducting (HTS) cryocooled system, operating at $77 \mathrm{~K}$ [15] (as far as is technologically possible) to reduce power losses associated with transitioning from an HTS system at 77K, to a warmer non-super conducting system [8]. It is acknowledged that any solid-state switching components within a distributed propulsion electrical architecture are unlikely to be superconducting, and assumed to operate at $100 \mathrm{~K}[8]$.

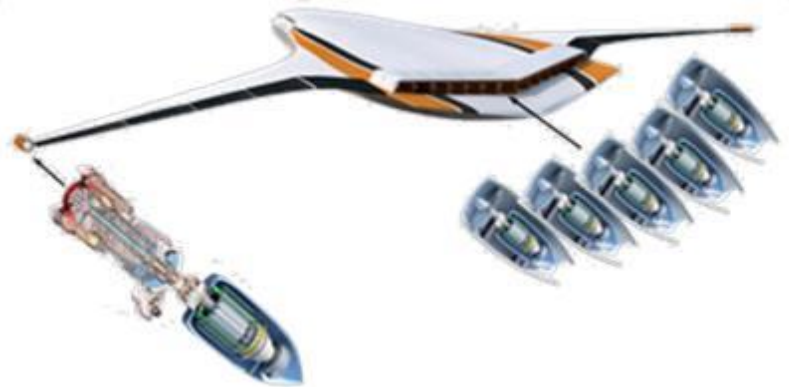

Fig. 1: NASA N3-X TeDP aircraft with wingtip mounted generators and propulsors along aft of the aircraft

Clearly the advantages of a superconducting power system must be traded against the mass and efficiency penalties attributable not only to the electrical components of the power system, but also the required cryogenic cooling system.

\section{CANDIDATE ARCHITECTURES}

This paper compares three candidate architectures identified from the literature: DC [8], hybrid AC-DC [10] and AC [9]. For the DC architecture, the transmission system is AC between the electric machines and power electronics, and DC throughout the transmission and distribution system. The other two candidate architectures have a transmission and distribution system which is purely variable frequency AC.

The DC architecture (Fig. 2) uses a predominantly DC power system to transmit and distribute power to the motors. To achieve this it includes both rectifiers and inverters, with a DC bus between the generators and motors. The DC architecture includes a protection system, comprising of a number of superconducting fault current limiters (SFCLs) and solid state circuit breakers (SSCBs), in all four sections of the electrical power network. This is the only one of the three candidate architectures which has a proposed protection system, therefore the electrical power system will be removed for comparative purposes. The motors and generators are electrically decoupled via the use of power electronic converters and a DC transmission and distribution network. This enables the generators to run at $8000 \mathrm{rpm}$ or higher, and the motors to run at $4000 \mathrm{rpm}$.

The hybrid AC-DC architecture (Fig. 3) shows the alternative proposal where the system is predominantly AC, with a back to back converter for each motor to allow independent speed optimization.

The AC architecture (Fig. 4) has no electronic decoupling between the generators and motors. To date this architecture has only been presented in the literature for a much smaller sized aircraft with 8 propulsor fans, with a total power demand of 9MW [9]. This architecture does not include any energy storage device for two reasons. Firstly the AC architecture presented in [9] did not include any energy storage. Secondly it is expected that an energy storage device would require a converter interface to the network, to ensure adequate controllability. A key aspect of this architecture is that it does not include any power electronic converters. In order to enable a fair comparison, the AC architecture considered in this paper has been scaled up in size to have the same power rating for the motors and generators as the other two baseline architectures. The elimination of a significant amount of 
This document is a pre-print which was accepted for publication in IEEE transactions on Applied Superconductivity on the $1^{\text {st }}$ of February 2016, and as such is subject to IEEE copyright.

power electronics in this architecture results in the generators and motors being run synchronously. However this removes the ability to control motor speed to adjust for thrust loads, and limits the ability to optimize system efficiency. The ability to restart under load must also be considered. There may be a requirement for mechanical decoupling or speed control between the technologies [9]. This will incur a mass penalty which is not accounted for in this study, but will be considered in the discussions.

The rated power levels for all three architectures include a significant level of redundancy to allow for scenarios such as engine out or loss of up to two propulsor motors [8]. For the purposes of this study, the required power for rolling take-off is estimated to be $22.4 \mathrm{MW}$ (30000 HP) [17]. Hence under normal operation, the motors will each require circa $1.4 \mathrm{MW}$ of electrical power. However, the four generators are each rated at $12.5 \mathrm{MW}$, and the 16 motors are each rated at $2.5 \mathrm{MW}$.

All three baseline architectures have additional redundancy with interconnection between the four main sub-systems powered by each generator, which reduces the motor rating, as indicated in Figs. 2-4. Interconnection may offer increased fault tolerance, as it may be possible to isolate faults and reroute power to a load [18], without the need for a complex network of extra cables for redundancy proposed in [19].

\section{PRE-DESIGN SENSITIVITY ANALYSIS}

In order to fully develop a superconducting distributed electrical power network, there is a need to be able to carry out high level power systems analysis to identify optimal operating points and the key elements impacting on system performance. As has been identified in the previous section, the key driver for the development of a power system for an aerospace application is system mass and efficiency, as these impact directly on fuel burn.

The authors have utilised a structured methodology which enables different baseline architectures to be compared for mass and efficiency, which is described in detail in [13]. This approach is easily reconfigurable to represent different architectures, due to its modular nature. A sensitivity model has been developed for each component within a distributed electrical propulsion power system: electrical machines, power electronic converters, cables, energy storage, solid state circuit breakers (SSCBs) and superconducting fault current limiters (SFCLs). A detailed description of these component sensitivity models, including the choice of component properties is provided in [15].

To maintain sufficient redundancy, a separate cryocooler is proposed for each set of components [7]. The power and mass for each cryocooler is modelled using equation (1) and equation (2). It is considered an achievable assumption that the percent of Carnot, $N_{\% c a r n o t}$, is $30 \%$ and that the cryocooler has a power density, $\mathrm{k}$, of $3 \mathrm{~kg} / \mathrm{kW}$ [2]. The full system efficiency $\left(\eta_{\text {full }}\right)$ is given by Equation (3) $P_{\text {motor }}$, is the total power demand of the motors, $P_{\text {cryo }}$ is the cryocooler power requirement and $P_{\text {elec_losses }}$ is the electrical losses in the system.
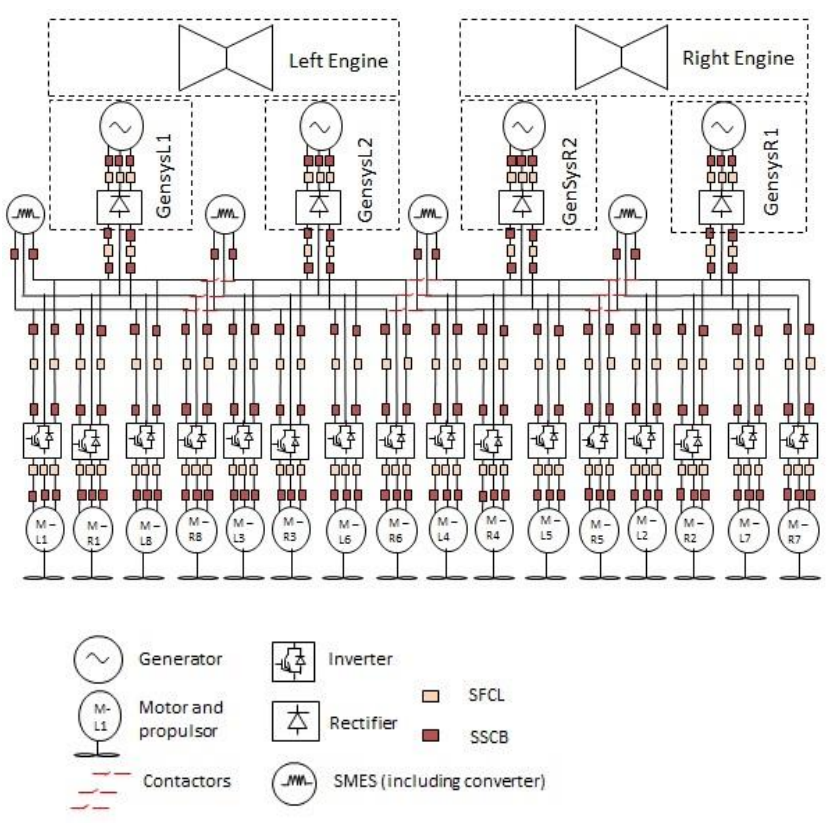

Fig. 2: DC architecture

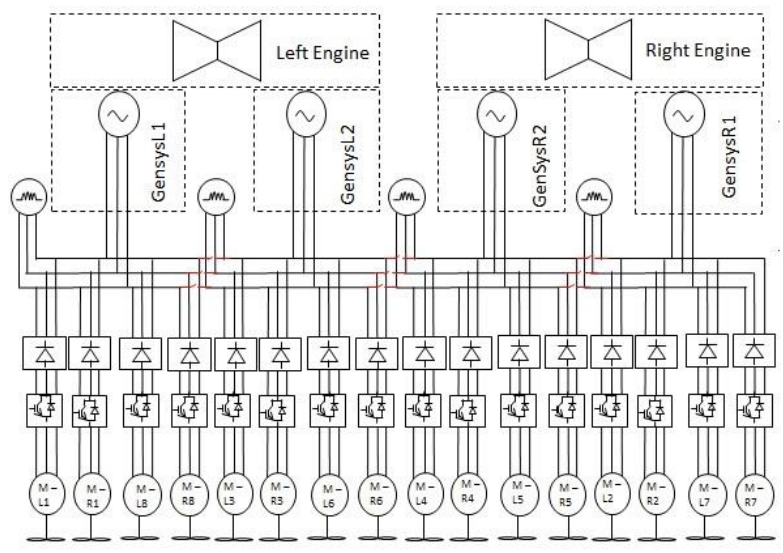

Fig. 3: Hybrid AC-DC architecture

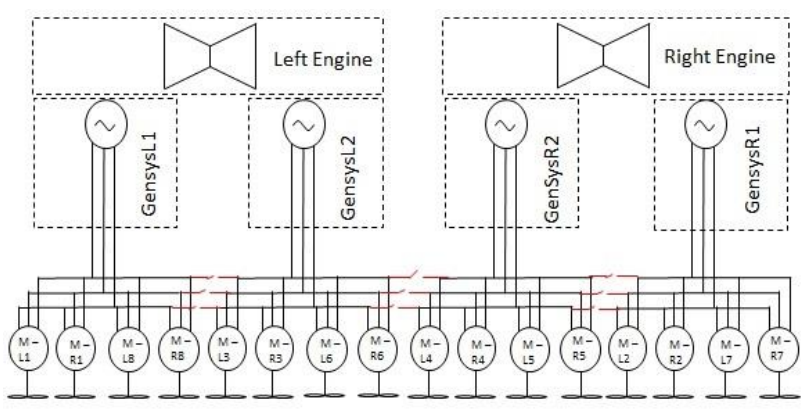

Fig. 4: AC architecture 
This document is a pre-print which was accepted for publication in IEEE transactions on Applied Superconductivity on the $1^{\text {st }}$ of February 2016, and as such is subject to IEEE copyright.

$P_{\text {cryo }}=\frac{\dot{Q}}{N_{\text {ocarnot }}} \frac{\left(T_{a m b}-T_{\text {cool }}\right)}{T_{\text {cool }}}$

$W_{\text {cryo }}=k \times P_{\text {cryo }}$

$\eta_{\text {full }}=\frac{P_{\text {motor }}}{P_{\text {motor }}+P_{\text {cryo }}+P_{\text {elec losses }}}$

$P_{c r y o}$ is the power required by a cryocooler (W) with an ambient temperature, $T_{a m b}(300 \mathrm{~K})$, and a coolant temperature, $T_{\text {cool }},(100 \mathrm{~K}$ and $77 \mathrm{~K}$ were used in this study) and $\dot{Q}$ is the heat flow to the coolant $(\mathrm{W})$. $W_{\text {cryo }}$ is the mass of the cryocooler $(\mathrm{kg})$. The ohmic losses and heat load in transitions between the superconducting power system and the nonsuperconducting power electronics have not been accounted for in this model.

The library of component models developed has been used to build a systems level sensitivity model for each of the three candidate architectures presented in Section III.

The physical shape of any proposed architecture will be determined by the dimensions of the aircraft and the positions of the generators and motors. As discussed earlier it has been proposed that the generators will be positioned on the wingtips, with the motors along the aft of the aircraft. From the dimensions presented in [6], this gives rise to the requirement to transmit the generated power a distance of circa $20 \mathrm{~m}$, to a distribution network, where it is then distributed to the propulsor motors.

Based on the estimated aircraft dimensions [7], the lengths of different sections of network cable were estimated for each candidate architecture and are presented in Fig. 5 and Table 2. The hybrid AC-DC architecture has a short (1m) DC link between the rectifier and inverter for each propulsion motors, with a further $1 \mathrm{~m}$ of $\mathrm{AC}$ cable from the inverter to the motor terminals.

\section{COMPARISON OF ARCHITECTURE PERFORMANCE}

A voltage sweep of each of the three identified architectures was conducted. From this the optimal operating voltage range for minimum mass and maximum efficiency for each candidate architecture was identified. A DC voltage sweep was undertaken for the DC and hybrid AC-DC architectures. A frequency sweep was also undertaken for the $\mathrm{AC}$ architecture. The graphical results are presented for the DC architecture. Mass and efficiency of the electrical machines are assumed to be generally insensitive to different voltage levels.

\section{A. DC Architecture Mass and Efficiency}

Fig. 6 shows the sensitivity of the mass of the proposed architecture to different levels of DC voltage, assuming that the switching losses of solid state switching converters are reduced by $50 \%$ compared to current IGBT technology operating at $100 \mathrm{~K}$. Reducing the solid state switching losses by $50 \%$ improves the efficiency (including the cryocooler) of the converters from $85 \%$ to $92 \%$, which is below the targeted efficiency of $99+\%$ [16]. From the data in Table 3 it is clear that the solid state switching components dominate the system mass and losses, and thereby the voltage profile of the architecture. Therefore, even though the mass and efficiency

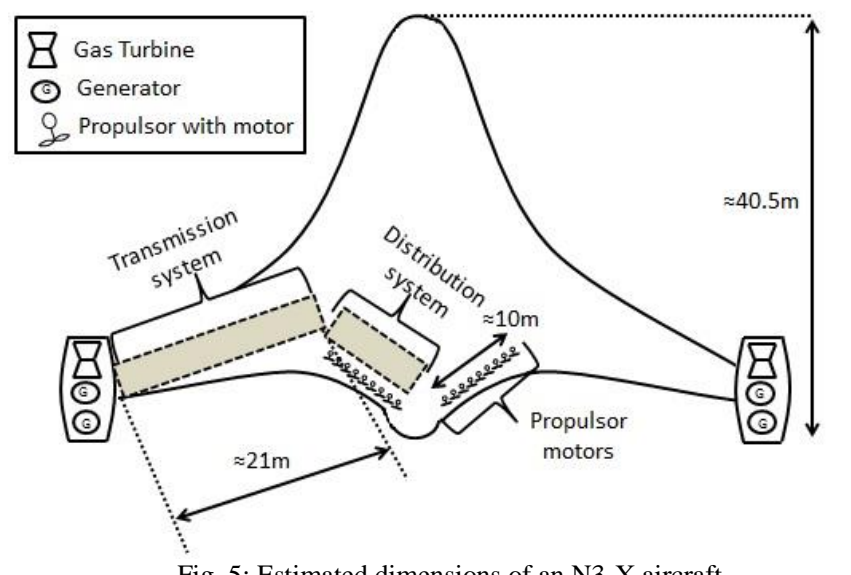

TABLE 2

Estimated CABLE LENGTHS FOR THE THREe CANDIDATE ARCHITECTURES

\begin{tabular}{|c|c|c|c|}
\hline & \multicolumn{3}{|c|}{ Length of section of network (m) } \\
\hline $\begin{array}{c}\text { Section of } \\
\text { network }\end{array}$ & $\begin{array}{c}\text { DC } \\
\text { architecture }\end{array}$ & $\begin{array}{c}\text { Hybrid AC- } \\
\text { DC } \\
\text { architecture }\end{array}$ & $\begin{array}{c}\text { AC } \\
\text { architecture }\end{array}$ \\
\hline $\begin{array}{c}\text { AC } \\
\text { Generator } \\
\text { Leads }\end{array}$ & 1 & $\mathrm{n} / \mathrm{a}$ & $\mathrm{n} / \mathrm{a}$ \\
\hline $\begin{array}{c}\mathrm{AC} \\
\text { transmission }\end{array}$ & $\mathrm{n} / \mathrm{a}$ & 22 & 22 \\
\hline $\begin{array}{c}\text { DC } \\
\text { Transmission }\end{array}$ & 21 & $\mathrm{n} / \mathrm{a}$ & $\mathrm{n} / \mathrm{a}$ \\
\hline $\begin{array}{c}\text { DC } \\
\text { Distribution }\end{array}$ & 9 & $\mathrm{n} / \mathrm{a}$ & $\mathrm{n} / \mathrm{a}$ \\
\hline DC link & $\mathrm{n} / \mathrm{a}$ & 1 & $\mathrm{n} / \mathrm{a}$ \\
\hline $\begin{array}{c}\text { AC } \\
\text { distribution }\end{array}$ & $\mathrm{n} / \mathrm{a}$ & 8 & 10 \\
\hline $\begin{array}{c}\text { AC motor } \\
\text { Leads }\end{array}$ & 1 & 1 & $\mathrm{n} / \mathrm{a}$ \\
\hline
\end{tabular}

of the electrical machines are insensitive to voltage level, the mass and efficiency of the integrated system are sensitive to voltage. The stair-step profile of the plot in Fig. 6 is due to the voltage profile of the solid state switching converters: the model of the components is such that when a threshold voltage level is reached, a different rating of component is used and hence there is a step in the profile. This result indicates that the operating voltage should be selected to be in a band from around $+/-2 \mathrm{kV}$ to $+/-4.5 \mathrm{kV}$, where the mass is at a minimum (absolute minimum is $3.486 \times 10^{4} \mathrm{~kg}$ at $+/-2 \mathrm{kV}$ ). Therefore there is some flexibility in the choice of voltage level. With the example protection system present, this rises to $6.044 \times 10^{4} \mathrm{~kg}$. As indicated in Table 3, the example protection system would account for $34 \%$ of system mass and $38 \%$ of system losses if included in the study. Only a very small percentage $(<1 \%)$ of the protection system mass and losses are attributable to the superconducting fault current limiters (SFCLs); the solid state circuit breakers (SSCBs) dominate. 
This document is a pre-print which was accepted for publication in IEEE transactions on Applied Superconductivity on the $1^{\text {st }}$ of February 2016, and as such is subject to IEEE copyright.

Of particular concern is that the majority of the mass $(70 \%)$ attributable to the cryocooler. From inspection of Table 3, it is clear that it is the converters and their cryocooling needs which are dominating the system mass. This is due to the comparatively high electrical losses of these components, which results in high cryogenic power requirements. This has serious implications not only for system mass but system efficiency (Fig. 7). The impact of further reducing converter losses to levels which are considered achievable for entry into service (EIS) in 2035, is included in the Section VI of this paper.

The results presented in Table 3 indicate that with this set of data, the minimal losses of the cables are outweighed by the high mass and losses penalty attributable to the converters.

The total system efficiency is calculated using equation (3). The electrical efficiency for the full system is $95 \%$, below the estimated targeted efficiency of $98 \%$ with cryocoolers [16]. However, when the cryogenic system is considered to calculate the total system efficiency, this falls to a maximum of $70.82 \%$ at $+/-2 \mathrm{kV}$ (Fig. 7).

The results indicate that the high power requirements of the cryocooler for this architecture configuration will require extra power generation, with the rating of the generators increased considerably, possibly up to $50 \mathrm{MW}$ per engine to maintain sufficient redundancy to cope with an engine out scenario. Increasing the generators to this size, would increase the mass of the system with the generators (and associated cryocoolers) increasing from $4775 \mathrm{~kg}$ (9.91\% of total mass) to $6247 \mathrm{~kg}$ (17 $\%$ of total mass). The overall system weight increases by $5 \%$. This estimate is conservative, as it does not consider the required increase in size of the rating the rectifier that interfaces the converter into the DC network. However, given the dominance of the solid state switching components on the mass and efficiency values, substantially increasing the rating of the generator will not have a huge impact on the overall mass and efficiency values.

\section{B. AC hybrid and AC architectures mass and efficiency}

Voltage sweeps were conducted for the DC architecture without protection, and the hybrid AC-DC architecture. Detailed results are not presented, but the optimum operating point of these architectures was found to be at $+/-1.8 \mathrm{kV}$. The optimal operating point of the $\mathrm{AC}$ architecture was found to be at $3.8 \mathrm{kVrms}$ per phase, with an $\mathrm{AC}$ frequency of $450 \mathrm{~Hz}$.

Table 4 shows the comparison of the optimum mass and efficiencies of the three candidate architectures. These are the combined cryogenic and electrical system mass and efficiencies. It is clear that the AC architecture is significantly lighter, by circa $29,800 \mathrm{~kg}$, and significantly more efficient than the DC and AC-DC architectures. It should be noted that the DC and hybrid AC-DC architectures include a superconducting magnetic energy storage (SMES) unit. This is not included in the $\mathrm{AC}$ architecture as it requires a converter, and hence is not considered for an $\mathrm{AC}$ architecture. Fig. 8 and Fig. 9 graphically present the component breakdown of system mass and losses for the three candidate architectures. It is clear that the converters included in the DC and AC-DC hybrid architectures contribute significantly (circa $75 \%$ ) to the system mass and losses (circa $85 \%$ ). The high electrical power losses from the converters result in a larger cryocooling system for the converters, in turn this impacts negatively on the mass and efficiency, resulting in the poor efficiencies and higher mass for these architectures shown in Table 4.

\section{DISCUSSION: COMPARISON OF ARCHITECTURES}

\section{A. DC architecture}

The DC architecture achieves electrical decoupling between electrical machines using power electronic converters with a DC transmission and distribution system. This allows the generators and motors to run at appropriate speeds to give optimal performance of the fan and engine: the generators can run at high speeds, thereby increasing engine efficiency (as discussed in Section II) and the motors can run at lower speeds with higher torque. In addition, the motors are electrically decoupled from each other. Hence it would be possible to operate different motors at different speeds. This may be beneficial following a transient event (such as an electrical fault, or bird strike), resulting in the loss of a propulsor. Additionally this increased functionality may benefit aircraft performance in terms of fuel burn. For example, during cruise, it may not be necessary to run all motors at the same speed.

Secondly, the DC architecture enables the straight forwards interfacing of a SMES unit into the architecture. The role of energy storage is yet to be fully defined for a TeDP aircraft. For more conventional electrical power systems, the role of high bandwidth energy storage is to provide support to voltage and power quality in response to system transients [20]. It is known that the advantages of including such functionality within a conventional electrical power system can lead to improved system efficiency, transient response and security of supply [20]. The inclusion of energy storage may also allow the overrating of the generators to be reduced, in turn reducing system mass and hence fuel burn.

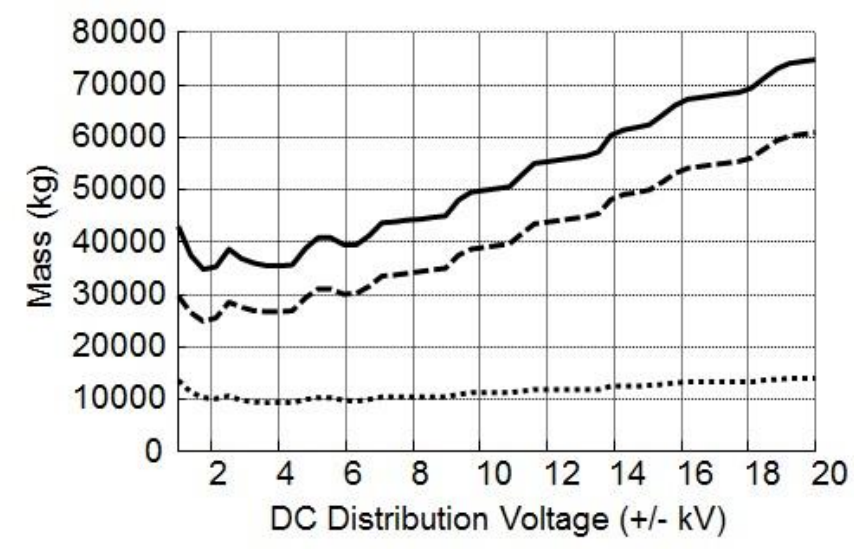

- Total mass

- - - Cryocooler mass

......... Electrical mass

Fig. 6: Total system mass of the DC architecture without protection, with breakdown to electrical and cryogenic cooling system contributions. 
This document is a pre-print which was accepted for publication in IEEE transactions on Applied Superconductivity on the $1^{\text {st }}$ of February 2016, and as such is subject to IEEE copyright.

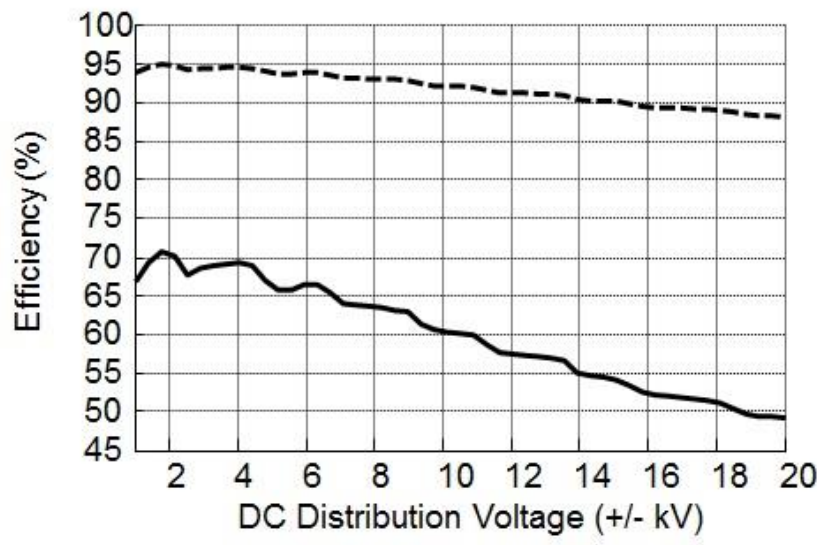

- Total efficiency

------ Electrical efficiency

Fig. 7: System efficiency of the DC architecture without protection, including cryogenic power requirements.

TABLE 3

MASS AND LOSSES BREAKDOWN FOR THE DC ARCHITECTURE WITHOUT PROTECTION. VALUES IN BRACKETS ARE FOR THE DC ARCHITECTURE WITH PROTECTION.

\begin{tabular}{|c|c|c|}
\hline Component & $\begin{array}{c}\text { Percentage } \\
\text { mass } \\
\text { contribution } \\
\text { relative to full } \\
\text { electrical } \\
\text { power system } \\
\text { mass (with } \\
\text { protection) }\end{array}$ & $\begin{array}{l}\text { Percentage losses } \\
\text { contribution } \\
\text { relative to full } \\
\text { electrical power } \\
\text { system losses } \\
\text { (with protection) }\end{array}$ \\
\hline Converters (\%) & $75.75(54.62)$ & $86.11(57.96)$ \\
\hline Electrical Machines (\%) & $13.70(7.90)$ & $4.41(2.52)$ \\
\hline SMES (\%) & $9.91(2.53)$ & $9.3(1.37)$ \\
\hline Cables (\%) & $0.62(0.31)$ & $0.18(0.077)$ \\
\hline Protection system (\%) & $\mathrm{n} / \mathrm{a}(34.62)$ & n/a (38.07) \\
\hline
\end{tabular}

TABLE 4

COMPARISON OF MASS AND EFFICIENCIES OF THE CANDIDATE ARCHITECTURES AT OPTIMAL OPERATING POINTS WITHOUT PROTECTION

\begin{tabular}{|c|c|c|c|}
\hline & \multicolumn{3}{|c|}{ Candidate Architecture } \\
\hline & DC & AC-DC & AC \\
\hline Efficiency (\%) & 70.82 & 72.44 & 97.47 \\
\hline Mass (kg) & 34860 & 32690 & 5065 \\
\hline
\end{tabular}

From the results presented for the DC architecture in this paper, the impact of the converters dominates system performance (mass and efficiency), making the high efficiency of the DC cables negligible on system performance. Whilst the benefits of a DC architecture are highly desirable, the converters incur a very high mass and efficiency, and hence fuel burn, penalty.

However, the development of TeDP architectures is at a very early stage. If the losses attributable to solid state switching losses could be reduced, then this may enable a DC architecture, and the benefits associated with electronic decoupling, to be realised for a TeDP power system. For example, if the solid state switching losses are decreased from $50 \%$ to $90 \%$ of the current IGBT losses operating at 100K,

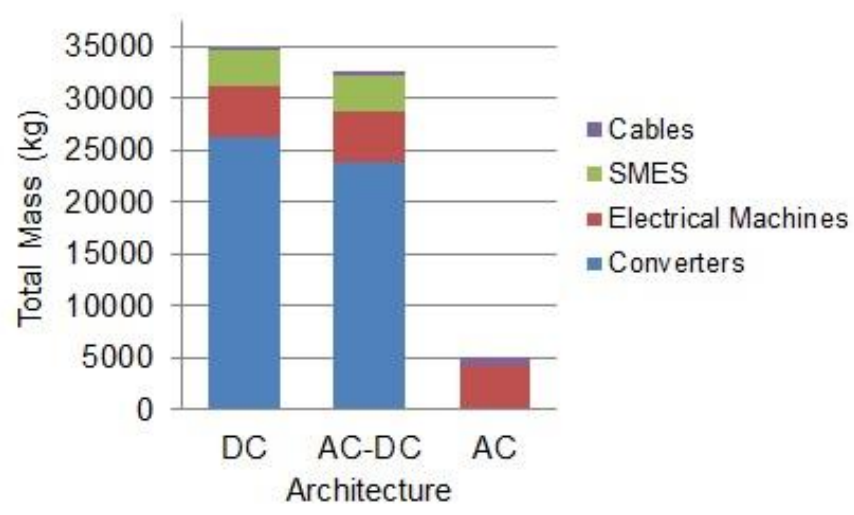

Fig. 8: Comparison of the breakdown of the mass of different architectures by component. The mass shown includes both the mass of the electrical components and the associated cryocooler system.

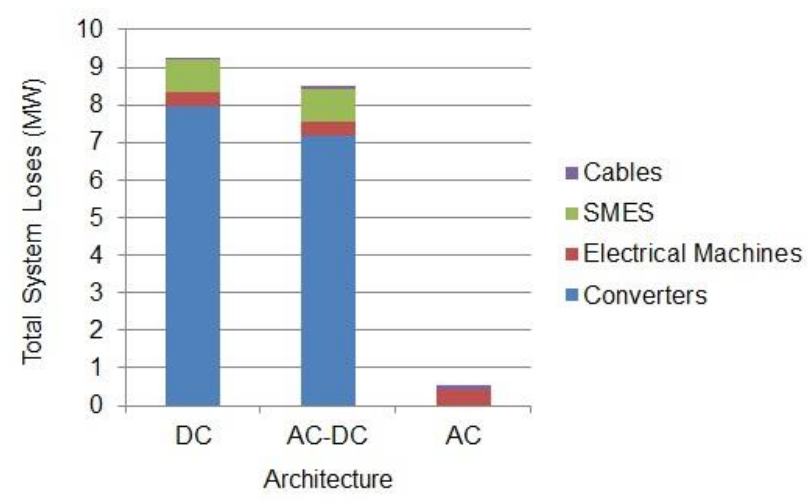

Fig. 9: Comparison of the breakdown of the combined electrical losses and cryocooler power requirements of the different architectures by component for each of the candidate architectures.

then the efficiency (including the cryocooler) of the converters rises to $98 \%$ from $92 \%$. As a result of this, as Fig. 10 and Fig. 11 indicate, the overall efficiency of the DC architecture increases by $20 \%$ to $90 \%$, with the mass decreasing by $50 \%$. Such a reduction in losses is not unrealistic, as it equates to a converter having an electrical efficiency of $99.8 \%$, which has been stated in the literature [10] as a realistic possibility for EIS by 2035 .

The choice of protection system will be inter-dependent on choice of architecture and levels of redundancy within the system. As Fig. 10 and Fig. 11 indicate, if the losses attributable to solid state switching components, which include SSCBs, can be significantly reduced then this may also influence protection choices.

\section{B. Hybrid AC-DC architecture}

The motors and generators are electrically decoupled in the hybrid AC-DC architecture, via a back to back converter on each propulsor motor feeder. This offers the same advantages as for the DC architecture. Due to the use of 16 lower rated rectifiers, compared to 4 higher rated rectifiers in the DC architecture, the performance in terms of mass and efficiency of the hybrid AC-DC architecture is better than the DC architecture (2\% more efficient and 6\% lighter), when the solid state switching components have $50 \%$ improvement in 
This document is a pre-print which was accepted for publication in IEEE transactions on Applied Superconductivity on the $1^{\text {st }}$ of February 2016, and as such is subject to IEEE copyright.

efficiency over current IGBT technology operating at 100K. However, by inspection of Fig. 10 and Fig. 11, if the solid state switching component efficiency improves by $90 \%$, then the AC-DC architecture is $6 \%$ heavier, and has the same efficiency as the DC only architecture. This indicates the importance of understanding how efficient future power electronics may be in developing an optimized, TeDP architecture.

The hybrid AC-DC architecture may offer lighter and more efficient protection options as it may be possible to use the fault current blocking properties of a current source rectifier to isolate a fault if it occurs downstream from a motor rectifier. However this may lead to an acceptance that a section of the faulted propulsion branch will quench, which may be undesirable due to possible damage to components [19].

\section{AC architecture}

Unlike the DC and hybrid AC-DC architecture, the AC architecture does not include any converters. Hence there is no electrical decoupling within the AC architecture. The clear advantage of this approach is the significant improvement in system mass and efficiency compared to the DC and hybrid AC-DC architectures. Hence, if only the mass and efficiency data is considered, the AC architecture is most likely to be able to be implemented on a TeDP aircraft without being detrimental to the increase in aircraft performance gained though a TeDP aircraft structure. The cable weight for the AC transmission and distribution system for both the AC-DC and $\mathrm{AC}$ architectures is much higher (more than twice the weight (AC-DC) and three times the weight (AC)), but this additional weight penalty in this study is insignificant due to the domination of the solid state switching losses of the converters.

However, several disadvantages to this approach have been identified. Firstly none of the advantages of electrical decoupling between electrical machines are realised. Hence a compromise may have to be found between running the generators at the optimum speed of the power turbine, and running the motors at a lower speed and higher torque [19].

To overcome this, a gear box could be included in the gas turbine. It is estimated that if a planetary gear box to reduce speed from $8000 \mathrm{rpm}$ to $4000 \mathrm{rpm}$ is placed on the generator then this would weigh around $130 \mathrm{~kg}$ per generator $(520 \mathrm{~kg}$ for a 4 generator architecture). This is for a gear box with $3 \mathrm{~mm}$ thick gears. If a gear box is required to be placed on each motor an additional $160 \mathrm{~kg}$ mass penalty would be incurred (10kg per motor). A gear box power loss of 4 to $5 \%$ is expected [16]. By inspection of Fig. 8, it is clear that with the inclusion of gear boxes, it is unlikely that the resulting $\mathrm{AC}$ architecture mass would exceed the mass of the DC or AC-DC architectures.

The gear box enables the electrical machines to run at optimised speeds, but the electrical machines remain directly coupled to each other unless mechanical speed control measures are installed (e.g. variable pitch propellers, which may also eliminate the need for gearing, but the adoption of which would incur a similar mass penalty). The electrical machines may be able to slip by a certain amount, allowing the possibility for additional slight variations in individual machine speeds. It may not always be desirable for all the

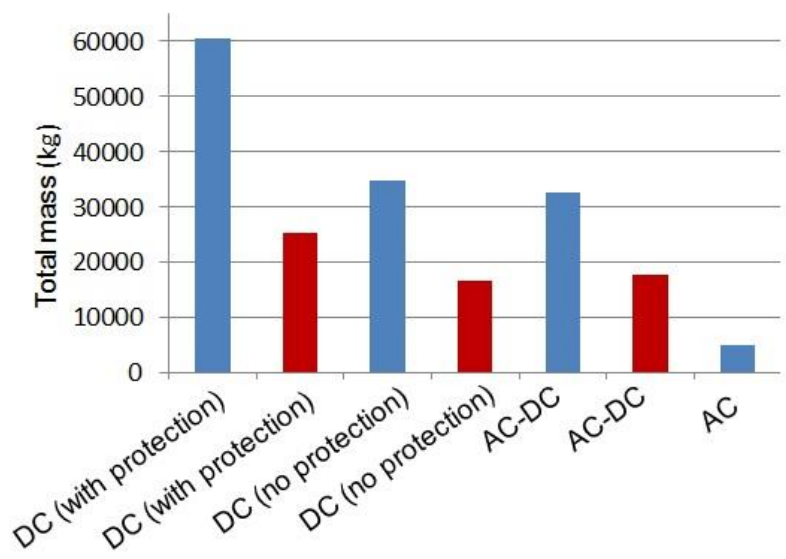

Fig. 10: Comparison of total system mass for the candidate architectures if the solid state losses are at $50 \%$ of the baseline level (blue) and then reduced to $90 \%$ of the baseline level (red).

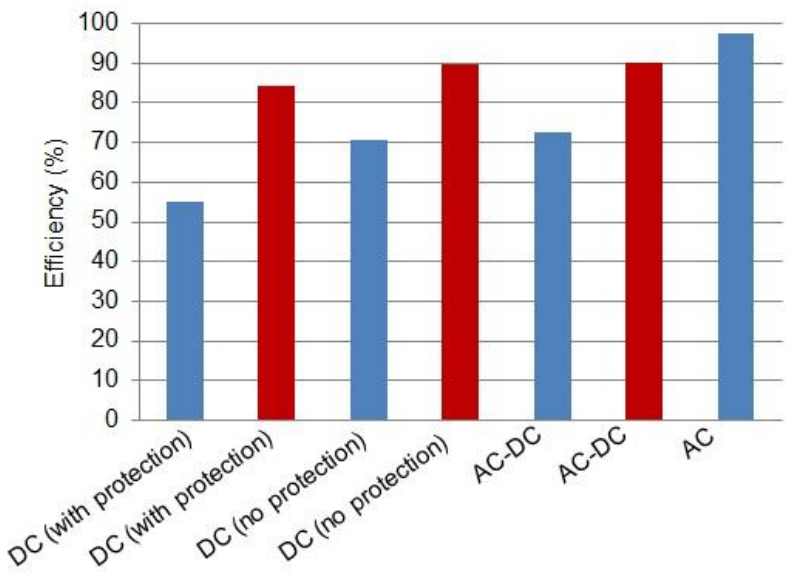

Fig. 11: Comparison of system efficiency for the candidate architectures if the solid state losses are at $50 \%$ of the baseline level (blue) and then reduced to $90 \%$ of the baseline level (red).

motors to be operating at the same speed. The levels, and effective bandwidth, of control over electrical machine speed and torque will be much lower compared to the DC and hybrid AC-DC architectures. There would be a mass penalty associated with control equipment to achieve and maintain synchronisation between the motors.

Secondly, whilst appropriate voltage standards have yet to be developed for TeDP aircraft, it is expected that the power factor will require to remain within appropriate limits. The power factor on current aero-electrical power systems must remain within 0.85 and 1.0 [21]. The inclusion of shunt capacitors would improve power quality [22]. In contrast to power factor control via power electronics, this solution does not provide dynamic power factor control. The inclusion of shunt capacitors would also incur a mass penalty.

Thirdly the AC architecture does not allow for the straight forwards inclusion of energy storage, due to the omission of converters. Hence the benefits of including energy storage are not realised. These may include a reduction in fuel consumption, and hence fuel burn, if energy storage can be used strategically to provide extra power at certain points in a flight cycle. If energy storage were to be considered for the AC system, the benefits would have to improve system 
This document is a pre-print which was accepted for publication in IEEE transactions on Applied Superconductivity on the $1^{\text {st }}$ of February 2016, and as such is subject to IEEE copyright.

performance very significantly, in order to offset the huge mass penalty that would be incurred: the mass of the SMES unit for the DC and hybrid AC-DC architectures is $3455 \mathrm{~kg}$; $70 \%$ of the mass of the full AC system.

Finally a protection system for the AC architecture has not been considered. Further studies are required to fully understand the fault response of AC superconducting networks, to develop a suitable protection framework and strategy. Quenching of the cables in response to a fault is unlikely to be satisfactory due to the possibility for fault propagation and damage to equipment. Hence other options (SFCLs and SSCBs) will need to be considered. If SSCBs are proposed, then by inspection of the results presented in Table 3 , this will have a significant negative impact on the performance of the $\mathrm{AC}$ architecture.

\section{CONCLUSIONS}

From the studies presented in this paper, it is clear that the $\mathrm{AC}$ architecture performs significantly better than the DC and hybrid AC-DC architectures in terms of mass and efficiency, primarily driven by the power conversion efficiency. This is due to the inclusion of power electronic converters in the DC and hybrid AC-DC architectures. However, questions surrounding the controllability and operation of the $\mathrm{AC}$ architecture remain. Whilst the studies conducted indicate that power electronic converters add a significant mass and efficiency penalty, this must be traded against the high levels of controllability that they bring to the system. In contrast a lower level of controllability, but with a much lower mass (and hence fuel burn penalty) may be achieved by the use of gear boxes or variable pitch propellers on an AC only system. A gear box does not allow the electrical machines to be decoupled, but does allow the speeds of the electrical machines to be optimised, and must address the power loss and reliability.

There is a clear need for dynamic studies to be carried out on all three architectures to ascertain if the perceived benefits of electrically decoupling the electrical machines outweigh the negative impact that these devices have on system performance. Additionally, research on solid state switching components may also significantly improve the operating efficiency and power density of power conversion systems, enhancing their suitability to the TeDP application.

In parallel to this, decisions must be made about how much redundant generator capacity is included on the aircraft. At present, due to the low efficiency of the converters with the required cryocooling, the results indicate that the rating of the generators would need to be significantly increased to provide sufficient redundancy for the system to be able to cope with an engine out scenario. How much redundancy is required within a distributed propulsion system, and the mass trade-off between this and a protection system, has to be studied. It is anticipated that there would be a fuel burn penalty associated with increasing the rating of the generators. A further study into the trades between increasing generator ratings and approaches to redundancy is required. Based on results and discussion presented in this paper, doubling the total rating of the generators to $50 \mathrm{MW}$ per engine, will increase the mass of the electrical generators by $5 \%$.
The study presented in this paper has only considered the performance of the system at peak power, which would occur during the take-off phase of flight. Whilst this is the section of flight that will have the highest power demand, it only accounts for a short section of the flight. Hence there is a need to study the power demand of the system over the full flight cycle to be able to fully investigate the performance of a candidate architecture and research if different architectures are more suited to long or short haul flight cycles.

From the study of the DC architecture it is clear that the protection system is likely to have a significant impact on system performance. This indicates that there is a real need to develop a protection strategy in partnership with the architecture development. Different architectures may require different protection solutions.

Finally, the role of bulk energy storage on a TeDP system needs to be investigated and defined, with a view to assessing the potential impact of bulk energy storage on efficiency and hence fuel burn. There is a need to minimise the use of energy storage to meet necessary operational functionality due to the associated weight penalty.

\section{ACKNOWLEDGMENT}

The authors thank the support of Rolls-Royce via the University Technology Centre for Electrical Power Systems with this paper. In particular, Christine Ross, formerly of Electrical Power and Control Systems, Rolls-Royce North America, Indianapolis, IN, USA., and Rory Steiger at RollsRoyce Plc, Derby, UK.

\section{REFERENCES}

[1] International Civil Aviation Organization, "Forecasts of scheduled passenger and freight traffic", [Online], Available: http://www.icao.int/sustainability/pages/eap_fp_forecastmed.aspx

[2] C.A. Luongo, P.J. Masson, T.Nam, D. Mavris, H.D. Kim, G.V. Brown, M. Walters and D. Hall, "Next generation more-electric aircraft: A potential application for HTS superconductors", IEEE Transactions on Applied Superconductivity, Vol. 19, pp. 1055 -1068, June 2009.

[3] Flightpath 2050 Europe's vision for aviation. European Commission. [online]. http://ec.europa.eu/transport/modes/air/doc/flightpath2050.pdf

[4] M.S. Ryerson, M. Hansen and J. Bonn, "Fuel consumption and operational performance", in $9^{\text {th }}$ USA/Europe Air Traffic Management Research and Development Seminar, 2011.

[5] R. Wahls. (2010). N+3 Technologies and concepts. Green Aviation Summit, NASA Ames Research Centre. Available: http://www.aeronautics.nasa.gov/pdf/wahls_2_green_aviation_summit.p df

[6] J.L.Felder, H.D. Kim and G.V. Brown, "An examination of the effect of boundary layer ingestion on turboelectric distributed propulsion systems", in $49^{\text {th }}$ American Institute of Aeronautics and Astronautics Aerospace Sciences meeting, 2011

[7] G.V. Brown, "Mass and efficiencies of electric components of a turboelectric aircraft propulsion system", in 49th American Institute of Aeronautics and Astronautics Aerospace Sciences Meeting, Orlando, FL., Jan. 2011.

[8] M. Armstrong, M. Blackwelder and C. Ross, "Sensitivity of TeDP microgrid systems mass and efficiency to operating voltage", in $50^{\text {th }}$ AIAA/ASME/SAE/ASEE Joint Propulsion Conference, 2014

[9] F. Berg, J. Palmer, P. Miller, M. Husband and G. Dodds, "HTS electrical system for a distributed propulsion aircraft", IEEE Transactions on Applied Superconductivity, Vol. 25, No. 3, June 2015

[10] H. D. Kim, G.V. Brown and J.L. Felder, "Distributed turboelectric propulsion for hybrid wing body aircraft", in International Powered Lift Conference, 2008. 
This document is a pre-print which was accepted for publication in IEEE transactions on Applied Superconductivity on the $1^{\text {st }}$ of February 2016, and as such is subject to IEEE copyright.

[11] J.L. Felder, M. T. Tong and J. Chu, "Sensitivity of mission energy consumption to turboelectric distributed propulsion design assumptions on the N3-X hybrid wing body aircraft", in $48^{\text {th }}$ AIAA/ASME/SAE/ASEE Joint Propulsion Conference, 2012.

[12] K. Karimi, "Future aircraft power systems - Integration challenges", The Boeing Company, 2007

[13] C. E. Jones, P. Norman, S. Galloway, G. Burt, M. Armstrong and A. Bollman, "A pre-design sensitivity tool for consideration of full-electric aircraft propulsion electrical power system architectures", in $3^{\text {rd }}$ International Conference on Electrical Systems for Aircraft, Railway, Ship Propulsion and Road Vehicles, Aachen, Germany, April 2015.

[14] P. Masson, D.S. Soban, E.Upton, J.E. Pienkos and C. A. Luongo, "HTS motors in aircraft propulsion: design considerations", IEEE Transactions on Applied Superconductivity, Vol.15, pp.2218-2221, 2005

[15] M.J. Armstrong, M. Blackwelder, A. Bollman, C. Ross, A. Campbell, C. Jones and P. Norman, "Architecture, voltage, and components for a turboelectric distributed propulsion electric grid", NASA/CR - 2015218440, 2015, [online]. Available: http://ntrs.nasa.gov/archive/nasa/casi.ntrs.nasa.gov/20150014237.pdf

[16] J. L. Felder, H. D. Kim and G. V. Brown, "Turboelectric distributed propulsion engine cycle analysis for hybrid-wing-body aircraft", $47^{\text {th }}$ AIAA Aerospace Sciences Meeting, Jan. 2009.

[17] M.J. Armstrong, C. A. H. Ross and M.J. Blackwelder, "Trade studies for NASA N3-X turboelectric distributed propulsion system electrical power system architecture", SAE International Journal of Aerospace, Oct. 2012

[18] A. Kwanski, "Advanced power electronics enabled distribution architectures: design, operation, and control", in $8^{\text {th }}$ International Conference on Power Electronics and ECCE Asia, May 2011.

[19] C. Ross, M. Armstrong, M. Blackwelder, C. Jones, S. Fletcher and P. Norman, "Turboelectric distributed propulsion protection system design trades", in SAE Aerospace Systems and Technology Conference, Cincinnati, OH., Sept. 2014.

[20] H. Zhang, F. Mollet, C. Saudemont and B. Robyns, "Experimental validation of energy storage system management strategies for a local DC distribution system of more electrical aircraft", IEEE Transactions on Industrial Electronics, Vol. 57, pp. 3905-3916, 2010.

[21] US Department of Defense, "Department of Defense Interface Standard: Aircraft Electric Power Characteristics. MIL-STD-704F", October 2013

[22] J. Ware, "Power factor correction (pfc)", IET Wiring Matters, Issue 18, 2006 